\title{
Cytogenetics of the Black Fly Simulium aureohirtum Brunetti from Thailand
}

\author{
Pairot Pramual ${ }^{1, *}$, Komgrit Wongpakam ${ }^{2}$ and Chaliow Kuvangkadilok ${ }^{3}$ \\ ${ }^{1}$ Department of Biology, Faculty of Science, Mahasarakham University, \\ Kantharawichai District, Maha Sarakham, 44150 Thailand \\ ${ }^{2}$ Walai Rukhavej Botanical Research Institute, Mahasarakham University, \\ Kantharawichai District, Maha Sarakham, 44150 Thailand \\ ${ }^{3}$ Department of Biology, Faculty of Science, Mahidol University, Rama VI \\ Road, Bangkok, 10400 Thailand
}

Received July 23, 2008; accepted September 23, 2008

\begin{abstract}
Summary The black fly, Simulium aureohirtum was geographically widespread, and encompasses a wide range of ecological conditions. A total of 1303 larvae from 21 sampling sites throughout Thailand were cytologically examined. Fourteen chromosome rearrangements were found and all were paracentric inversions. Most inversions (12 of 14) were present at low frequency and geographically restricted to a particular population, suggesting they originated recently. Significant genetic differentiation between populations were detected $\left(F_{\mathrm{ST}}=0.092, p=0.0002\right)$. Detection of an isolation by distance $(r=0.497, p=0.004)$ suggests that gene flow was limited by geographic distance. Inversion frequency of IIL-1 was significantly associated with latitude $(r=0.832, p<0.01)$, altitude $(r=0.471, p<0.05)$ and minimum annual air temperature $(r=-0.748, p<0.01)$ indicating that it might be maintained in populations by selection. The frequency of IIL-2 was significantly associated with altitude $(r=0.778, p<0.01)$ and minimum annual air temperature $(r=-0.570, p<0.01)$ but because it was present at low frequency $(<7 \%)$, selection probably was not involved. This inversion more likely represents a relict of ancestral polymorphisms. Comparison of the chromosome banding patterns revealed that $S$. aureohirtum is more closely related to $S$. ruficorne than to the $S$. ornatipes complex.
\end{abstract}

Key words Simulium, Polytene chromosome, Cline, Chromosome polymorphisms

Banding patterns of the salivary gland polytene chromosomes of black flies are useful for both taxonomy and population genetic study. Comparison of chromosome sequences can reveal taxonomic status, relationships between species and the role of chromosomal changes on local adaptation and speciation (e.g. Bedo 1979a, b, 1989, Leonhardt and Feraday 1989, Kuvangkadilok et al. 1999, 2003, Adler and Kachvorian 2001, Hunter 2002). It has been proposed that, based on chromosome study, speciation in black flies was initiated or mediated by chromosome rearrangement (Rothfels 1989). The model of speciation in black flies proposed by Rothfels (1989), suggests that chromosome rearrangements should be involved in local adaptation.

Cytogenetic studies in Drosophila that have detected an association between chromosome rearrangements and environmental or geographical factors (i.e. clinal variation) such as climate (e.g. Dobzhansky 1948, Knibb 1982, Rodríguez-Trelles et al. 1996, Unima et al. 2005, Etges et al. 2006), elevation (e.g. Ananina et al. 2004) or latitude (Stalker 1980, Knibb et al. 1981) provide evidence that chromosome rearrangements are involved in local adaptation. However, clinal variation in black flies has rarely been reported. Only one study found a relationship between inversion frequency and altitude and water velocity in Simulium; Charalambous et al. (2005) found significant association of inversion frequency with altitude and water velocity in S. exiguum.

* Corresponding author, e-mail: pairot.p@msu.ac.th 


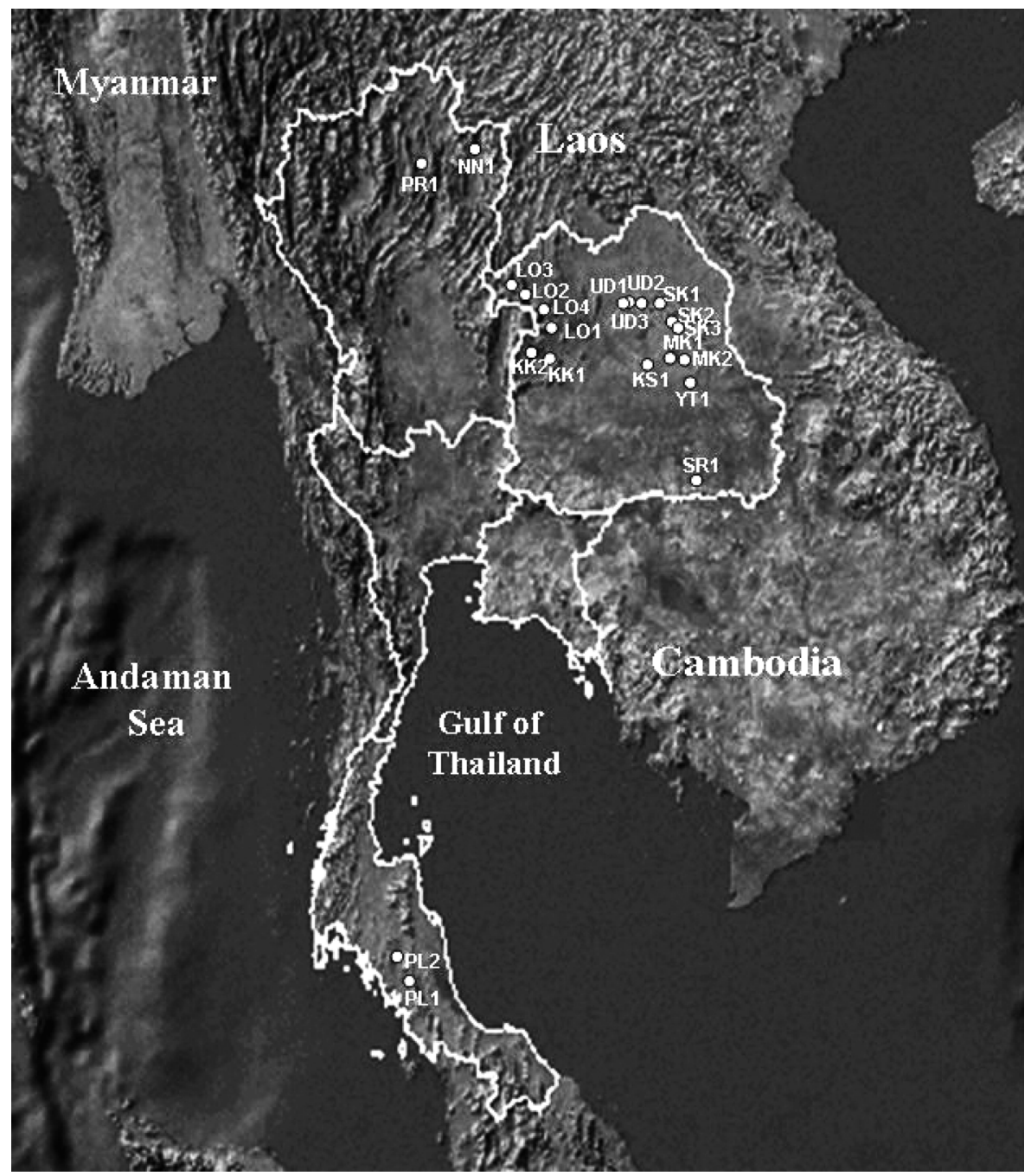

Fig. 1. Sampling locations of Simulium aureohirtum in Thailand, details of each site are shown on Table 1.

Simulium aureohirtum Brunetti (1911) was assigned to S. ruficorne species group of the subgenus Simulium based on morphology (Crosskey 1969). This species is geographically widespread throughout the Oriental region and some parts of the Palaearctic (Takaoka and Davies 1996). It has been found in Japan, Taiwan, China, Bhutan, Nepal, Pakistan, Sri Lanka, Thailand and Malaysia (Adler and Crosskey 2008). Ecologically this species occurs in small, shallow streams often found associated with outlets from human-made ponds or human-made channels in the irrigation fields (Takaoka and Davies 1996).

Cytogenetic studies of the members of the $S$. ruficorne group, including $S$. ruficorne (Bedo 1989), S. ornatipes and S. neornatipes (Bedo 1977), revealed a close relation between these species, according to homology of the chromosome banding patterns (Bedo 1989). However, these species are geographically isolated, Simulium ornatipes is found in Australia, New Guinea and Indonesia and $S$. neornatipes is found in New Caledonia, whereas S. ruficorne is found in Africa and the Middle East (Adler and Crosskey 2008). Thus studies of species that are distributed in geographically intermediate areas (i.e. Asia) could be interesting for understanding species relationships. In addition, 
Table 1. Details of 21 sampling locations of Simulium aureohirtum in Thailand

\begin{tabular}{|c|c|c|c|c|}
\hline Location (code) & $\mathrm{N}$ & Latitude/longitude & Altitude (m) & Date \\
\hline Thung Chang, Nan (NN1) & 15 & $19^{\circ} 22^{\prime} 15^{\prime \prime} \mathrm{N} / 100^{\circ} 52^{\prime} 32^{\prime \prime} \mathrm{E}$ & 313 & 07.01 .07 \\
\hline Ban Tha Klong, Phrae (PR1) & 106 & $19^{\circ} 17^{\prime} 03^{\prime \prime} \mathrm{N} / 99^{\circ} 48^{\prime} 27^{\prime \prime} \mathrm{E}$ & 411 & 19.02 .06 \\
\hline Ban Kang Sri Phume, Loei (LO1) & 77 & $17^{\circ} 03^{\prime} 58^{\prime \prime} \mathrm{N} / 101^{\circ} 41^{\prime} 59^{\prime \prime} \mathrm{E}$ & 299 & 30.06 .07 \\
\hline Ban Huai Lak, Loei (LO2) & 164 & $17^{\circ} 45^{\prime} 08^{\prime \prime} \mathrm{N} / 101^{\circ} 42^{\prime} 58^{\prime \prime} \mathrm{E}$ & 736 & 14.10.07 \\
\hline Phu Ruea, Loei (LO3) & 46 & $17^{\circ} 50^{\prime} 34^{\prime \prime} \mathrm{N} / 101^{\circ} 34^{\prime} 52^{\prime \prime} \mathrm{E}$ & 1302 & 14.10 .07 \\
\hline Ban Tam Mun, Loei (LO4) & 103 & $17^{\circ} 42^{\prime} 06^{\prime \prime} \mathrm{N} / 101^{\circ} 53^{\prime} 19^{\prime \prime} \mathrm{E}$ & 545 & 14.10.07 \\
\hline Wang Yai Reservoir, Udon Thani (UD1) & 30 & $17^{\circ} 01^{\prime} 34^{\prime \prime} \mathrm{N} / 103^{\circ} 31^{\prime} 09^{\prime \prime} \mathrm{E}$ & 195 & 10.02 .07 \\
\hline Ban Dan Bon 1, Udon Thani (UD2) & 18 & $17^{\circ} 08^{\prime} 10^{\prime \prime} \mathrm{N} / 103^{\circ} 29^{\prime} 56^{\prime \prime} \mathrm{E}$ & 224 & 04.03 .07 \\
\hline Ban Dan Bon 2, Udon Than (UD3) & 21 & $17^{\circ} 08^{\prime} 08^{\prime \prime} \mathrm{N} / 103^{\circ} 29^{\prime} 59^{\prime \prime} \mathrm{E}$ & 253 & 04.03 .07 \\
\hline \multirow[t]{2}{*}{ Kham Yom Reservoir, Sakon Nakhon (SK1)* } & 24 & $17^{\circ} 12^{\prime} 58^{\prime \prime} \mathrm{N} / 103^{\circ} 35^{\prime} 51^{\prime \prime} \mathrm{E}$ & 226 & 10.02.07 \\
\hline & 125 & & & 01.12 .07 \\
\hline Ban Sang Keaw 1, Sakon Nakhon (SK2) & 10 & $16^{\circ} 49^{\prime} 52^{\prime \prime} \mathrm{N} / 103^{\circ} 57^{\prime} 51^{\prime \prime} \mathrm{E}$ & 303 & 13.01 .07 \\
\hline Ban Sang Keaw 2, Sakon Nakhon (SK3) & 86 & $16^{\circ} 49^{\prime} 51^{\prime \prime} \mathrm{N} / 103^{\circ} 57^{\prime} 38^{\prime \prime} \mathrm{E}$ & 294 & 14.07.07 \\
\hline Ban Na Fai, Khon Kean (KK1) & 143 & $16^{\circ} 39^{\prime} 45^{\prime \prime} \mathrm{N} / 101^{\circ} 51^{\prime} 52^{\prime \prime} \mathrm{E}$ & 252 & 11.02 .07 \\
\hline Tad Tao WF, Khon Kean (KK2) & 16 & $16^{\circ} 40^{\prime} 50^{\prime \prime} \mathrm{N} / 101^{\circ} 51^{\prime} 16^{\prime \prime} \mathrm{E}$ & 273 & 11.02.07 \\
\hline Ban Nam Kham, Kalasin (KS1) & 20 & $16^{\circ} 40^{\prime} 42^{\prime \prime} \mathrm{N} / 103^{\circ} 58^{\prime} 11^{\prime \prime} \mathrm{E}$ & 156 & 13.01 .07 \\
\hline Ban Kok Tum, Mukdahan (MK1) & 60 & $16^{\circ} 45^{\prime} 52^{\prime \prime} \mathrm{N} / 104^{\circ} 10^{\prime} 32^{\prime \prime} \mathrm{E}$ & 278 & 23.12 .06 \\
\hline Ban Suan Sa Wan, Mukdahan (MK2) & 33 & $16^{\circ} 45^{\prime} 55^{\prime \prime} \mathrm{N} / 104^{\circ} 10^{\prime} 52^{\prime \prime} \mathrm{E}$ & 260 & 14.07.07 \\
\hline Ban Rom Klaow, Yasothon (YT1) & 33 & $16^{\circ} 08^{\prime} 59^{\prime \prime} \mathrm{N} / 104^{\circ} 49^{\prime} 35^{\prime \prime} \mathrm{E}$ & 177 & 25.03 .07 \\
\hline \multirow[t]{2}{*}{ Ban Na Tum Bon, Sri Sa Ket (SR1)* } & 33 & $14^{\circ} 26^{\prime} 53^{\prime \prime} \mathrm{N} / 104^{\circ} 03^{\prime} 52^{\prime \prime} \mathrm{E}$ & 188 & 30.06 .07 \\
\hline & 44 & & & 09.12 .07 \\
\hline Ban Nai Mon, Phatthalung (PL1) & 93 & $07^{\circ} 26^{\prime} 57^{\prime \prime} \mathrm{N} / 99^{\circ} 55^{\prime} 44^{\prime \prime} \mathrm{E}$ & 63 & 11.12 .06 \\
\hline Nan Pliw Water fall, Phatthalung (PL2) & 60 & $07^{\circ} 34^{\prime} 24^{\prime \prime} \mathrm{N} / 99^{\circ} 56^{\prime} 27^{\prime \prime} \mathrm{E}$ & 54 & 11.12 .06 \\
\hline
\end{tabular}

Note: N, sample size; * samples were collected twice.

because $S$. aureohirtum is geographically widespread, it is also of interest regarding the role of chromosome polymorphisms in adaptation. The objectives of this study are (i) to infer species relationships of $S$. aureohirtum with other species, using polytene chromosome banding patterns, and (ii) to quantify the level of chromosome polymorphism and the role of chromosome changes in local adaptation.

\section{Materials and methods}

\section{Black fly samples and identification}

Black flies were collected from 21 sites throughout Thailand from February 2006 to December 2007 (Fig. 1, Table 1). Larvae and pupae attached to substrates such as trailing grass and fallen leaves, were collected using fine forceps. Larvae were place in freshly prepared Carnoy's fixative ( $3: 1 ; 95 \%$ ethanol : glacial acetic acid). Fixative was changed within $10 \mathrm{~min}$ and again after $24 \mathrm{~h}$. Samples were store at $-20^{\circ} \mathrm{C}$ until chromosome preparation. Larvae of Simulium aureohirtum were morphologically identified using the key of Takaoka (1979). Environmental conditions of the sampling sites were measured following the method described by McCreadie et al. (2006).

\section{Polytene chromosome preparation and banding pattern analysis}

Penultimate larvae were subjected to salivary gland polytene chromosome preparation following the Feulgen method described by Rothfels and Dunbar (1953). Well-spread and high-quality slides were photographed and used to construct the standard polytene chromosome map. Chromosome sections were numbered following the standard map of $S$. ornatipes (Bedo 1977). Salivary gland polytene chromosomes were analyzed band for band with the standard map and chromosome 

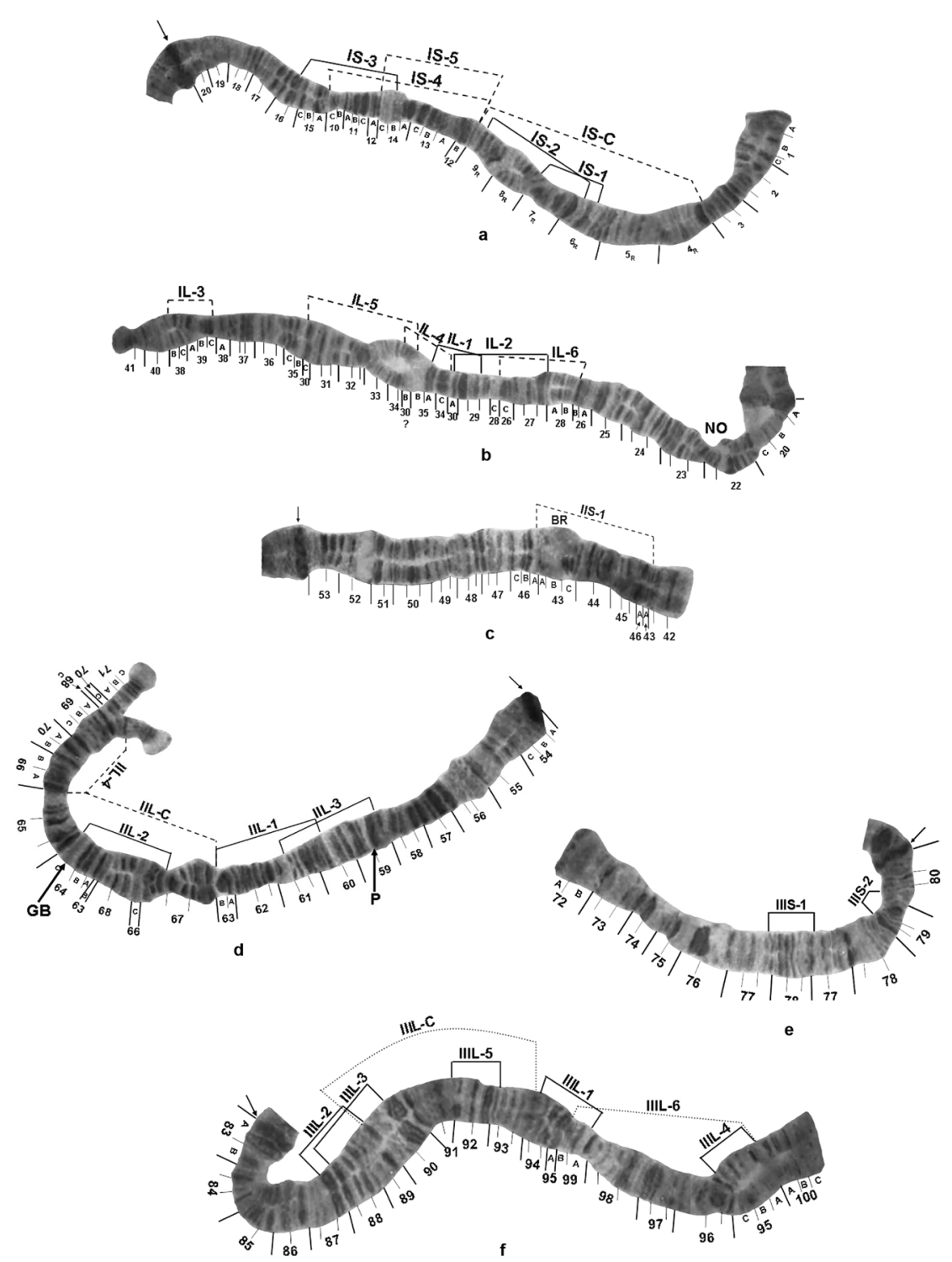

Fig. 2. Standard polytene chromosome map of Simulium aureohirtum. Brackets indicate the position of the inversion. Dotted line bracket indicates fixed inversion relative to $S$. ornatipes or S. ruficorne standard map. The centromeric region is indicated by arrow. Sections of the chromosome were numbered following those of $S$. ornatipes. NO, Nucleolar organizer. BR, Balbiani ring. P, parabalbiani, GB, grey band. The sections with subscript $\mathrm{R}$ denote the section of complex inversion IS-C. $\mathrm{a}=\mathrm{IS}$, $\mathrm{b}=\mathrm{IL}, \mathrm{c}=\mathrm{IIS}, \mathrm{d}=\mathrm{IIL}, \mathrm{e}=\mathrm{IIIS}, \mathrm{f}=\mathrm{IIIL}$.

rearrangements were record. Names of the inversions followed the order of discovery (e.g. IS-1 was found before IS-2).

\section{Data analysis}

Data from SK1 and SR1, which were sampled twice, were pooled, as the test of heterogeneity of inversion frequencies were not significant $\left(\chi^{2}=1.535, p=0.909\right.$ for SK1 and $\chi^{2}=1.540, p=0.215$ for SR1). Hardy-Weinberg equilibrium was assessed for each population, using a $G$-test $(p=0.05)$. 


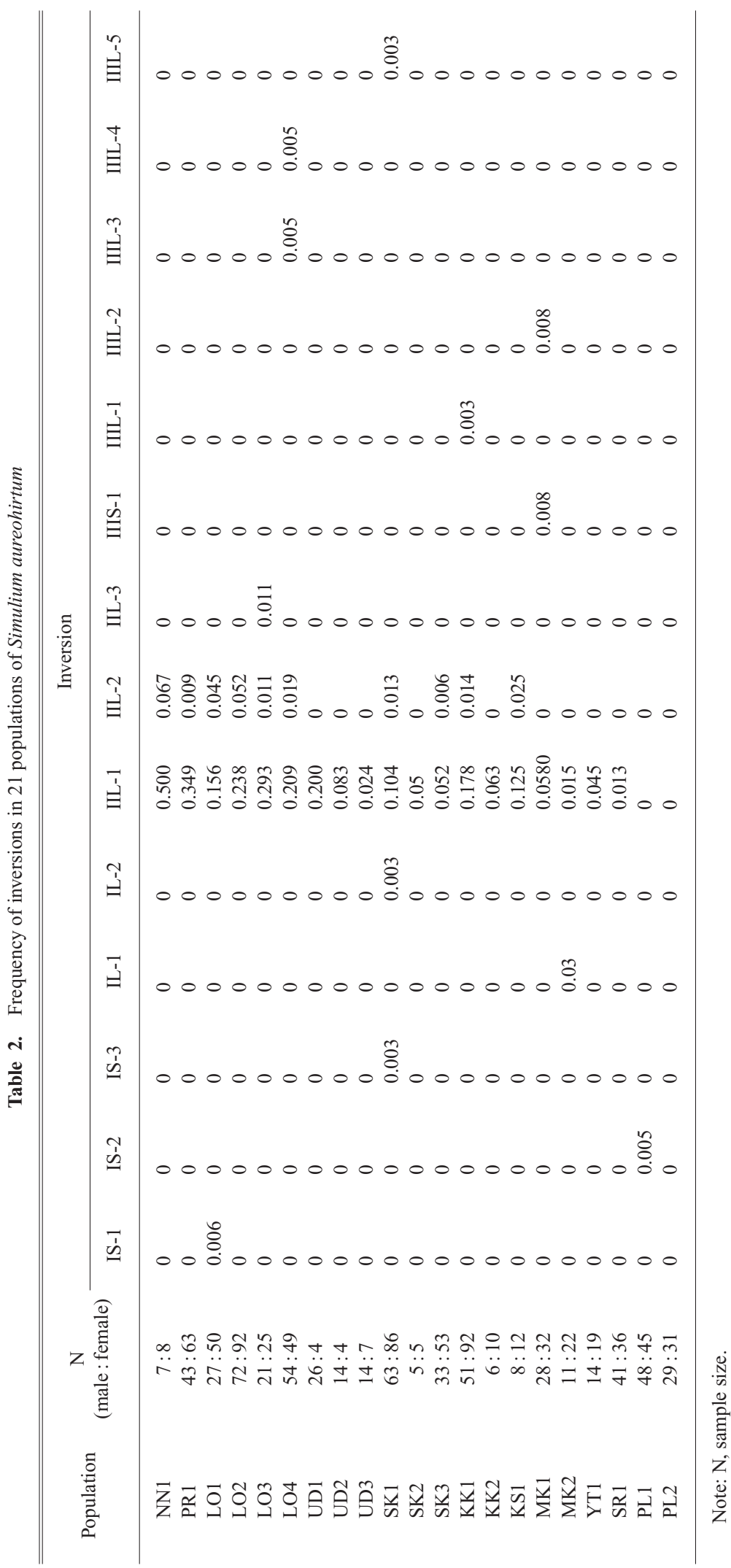


Genetic differentiation between populations was analyzed using Wright's $F$-statistics calculated following the method of Weir and Cockerham (1984). The statistical tests were based on randomization of the data in 6,500 replications. Linkage disequilibrium was tested between all possible pairs of inversions using 1,000 permutations. Genetic structure and linkage disequilibrium analyses were performed using the computer software FSTAT (Goudet 1995, 2001). Nei's modified genetic distances $\left(D_{A}\right)$ based on inversion frequencies were calculated to assess levels of genetic differentiation between populations using the computer program DISPAN (Ota 1993). A Mantel (1967) test was used to determine the relationship between genetic distance ( $\mathrm{D}_{\mathrm{A}}$ from DISPAN) and geographic distance $(\mathrm{km})$ (i.e. isolation by distance model). The Mantel test was implemented in IBD 1.52 (Bohonak 2002) using 5000 randomizations.

The relationships between inversion frequency and environmental conditions ( $\mathrm{pH}$, water conductivity, water velocity, stream discharge, and water temperature) were examined using the Pearson correlation. All inversion frequencies were angular transform prior to analysis. Correlations were also assessed between inversion frequency (after angular transform) and average minimum and maximum annual air temperature. The minimum and maximum annual air temperatures were calculated by averaging the lowest (for minimum annual temperature) and the highest (for maximum annual temperature) temperature for five years (2002 to 2006). Because large sampling gap existed between two sampling sites in the south (PL1 and PL2) and other sites, these two populations were omitted for correlation analyses.

\section{Results}

\section{Chromosome morphology of Simulium aureohirtum}

Simulium aureohirtum has three pairs $(2 n=6)$ of chromosomes, I, II, and III, each with two arms. The standard map of this species is shown in Fig. 2. Chromosome I is the longest chromosome, with $41 \%$ of the total chromosome length (Fig. 2a, b). The prominent nucleolar organizer (NO) located in section 22 of IL is a useful marker for chromosome identification. The find bands at the end of IS (section 1A) and group of dark bands in section 16 are also useful for chromosome identification. Chromosome II is submetacentric. This chromosome is shorter than chromosome I, with $30 \%$ of the total length (Fig. 2c, d). Several chromosome markers were found on chromosome II. The three dark bands on section 53 at the base of IIS and the presence of the ring of Balbiani (BR) in section 43 are useful markers for chromosome identification. On the long arm, the parabalbiani (PB) in section 59A and the grey band (GB) in section 64C are useful for chromosome analysis. Chromosome III is the shortest, with $29 \%$ of the total length (Fig. 2e,f). This chromosome is submetacentric with a higher arm ratio than for chromosome II. The heavy, dark band in section $76 \mathrm{~A}$ of IIIS is a useful marker for chromosome identification. On the long arm, groups of dark bands in section $87 \mathrm{C}$ to 88 and $90 \mathrm{~B}$ are useful for chromosome analysis.

\section{Chromosome polymorphism}

A total of 1303 larvae were cytologically examined. Fourteen chromosome rearrangements were found and all of these are paracentric inversion. Most inversions (12 of 14) were present at low frequency (Table 2) and geographically restricted to a particular population (i.e. rare inversion). Only two inversions (IIL-1 and IIL-2) were present at high frequencies and geographically widespread. Inversion IIL-1 was the most widespread being found in all but two populations in the south (PL1 and PL2).

All populations were in Hardy-Weinberg equilibrium, except for a significant excess of heterozygotes of IIL-1 inversion at PR1 $(G=6.17, p=0.038)$. Significant differentiations for number of heterozygotes of IIL-1 between sexes were detected in three populations (Table 3). A number of heterozygotes in female were significantly more than in male at KK1 $\left(\chi^{2}=5.83, p=0.016\right)$ and PR1 


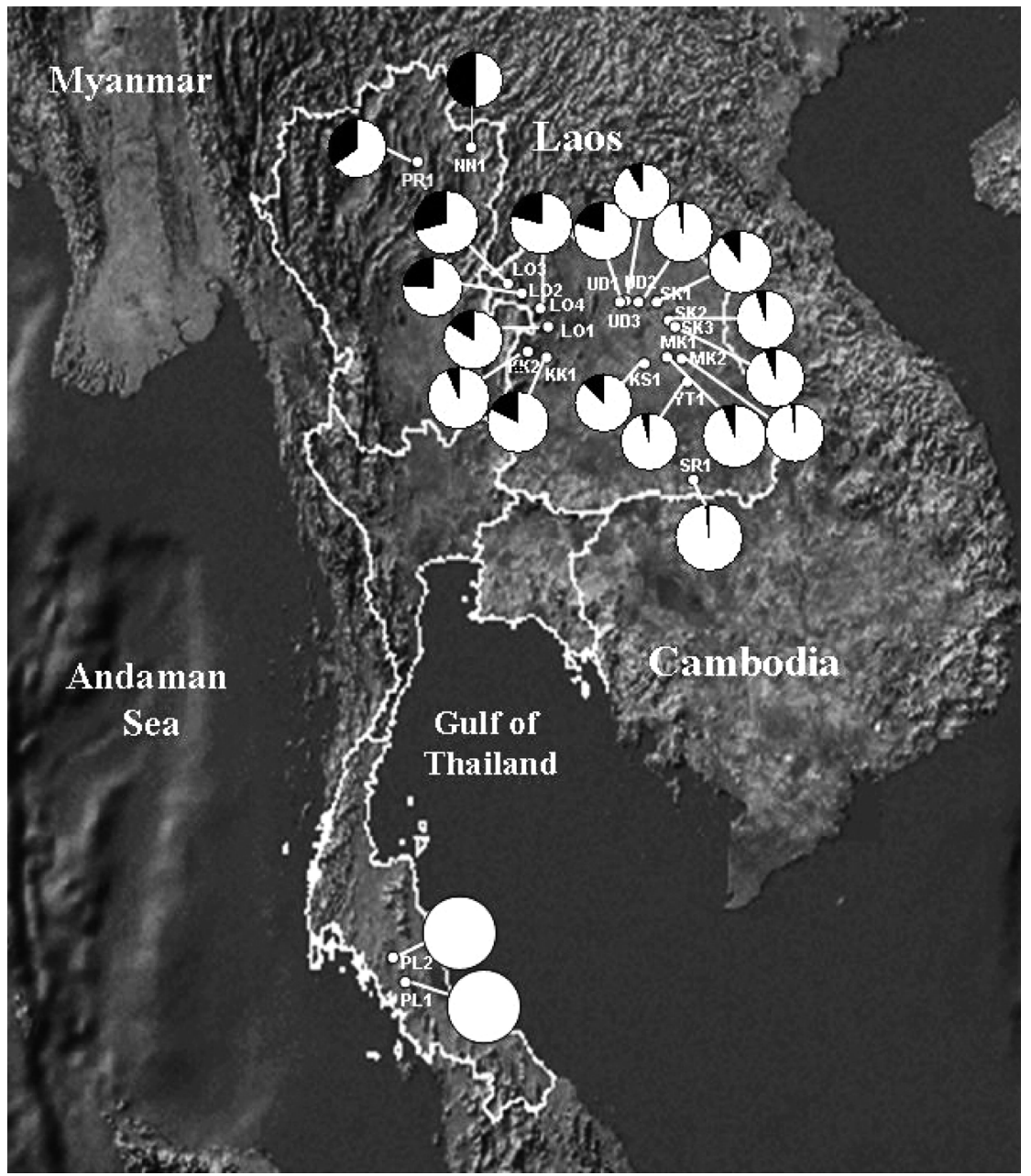

Fig. 3. Diagram showing frequencies of IIL-1 inversion (black) and standard sequence (white) in each population in Thailand.

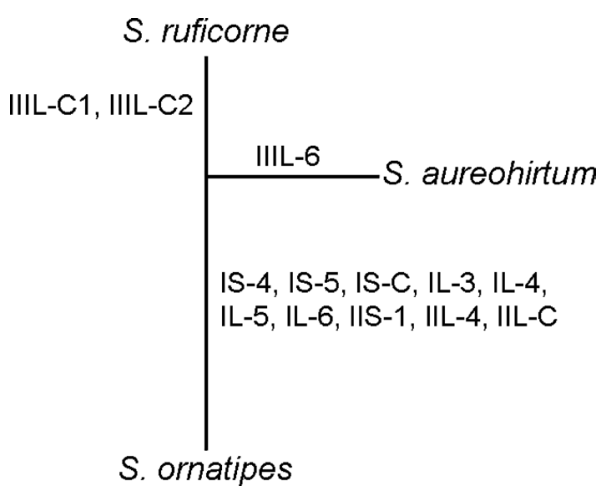

Fig. 4. Relationships among Simulium aureohirtum and S. ruficorne, and S. ornatipes. Chromosome inversions that are fixed among species are shown on the branch.
Table 3. Distribution of the IIL-1 inversion in male and female in three populations of Simulium aureohirtum where significant different for a number of heterozygotes inversion between sexes were found

\begin{tabular}{clrrc}
\hline \hline Population & Sex & SS & Si & $\chi^{2}$ \\
\hline \multirow{2}{*}{ KK1 } & Male & 41 & 8 & $5.83^{*}$ \\
& Female & 71 & 21 & \\
PR1 & Male & 18 & 22 & $4.74^{*}$ \\
& Female & 20 & 39 & \\
UD1 & Male & 15 & 11 & $8.33^{*}$ \\
& Female & 3 & 1 & \\
\hline
\end{tabular}

Note: ${ }^{*} p<0.05$; SS, standard homozygote; Si, heterozygote. 
$\left(\chi^{2}=4.74, p=0.030\right)$ but the opposite situation found at UD1; number of heterozygotes in male were significantly more than in female $\left(\chi^{2}=8.33, p=0.004\right)$.

Population genetic structure analysis revealed a significant genetic differentiation between populations $\left(F_{\mathrm{ST}}=0.092, p=0.0002\right)$. However, Nei's modified genetic distances $\left(\mathrm{D}_{\mathrm{A}}\right)$ between populations were low with an average of 0.004 . The relationship between geographic $(\mathrm{Km})$ and genetic distance $\left(\mathrm{D}_{\mathrm{A}}\right.$ values from DISPAN) between populations was significant $(r=0.497, p=0.004)$.

Pearson correlation analyses revealed a significant relationship between inversion frequency and geographical and environmental factors. Inversion IIL-1 had a positive significant relationship with latitude $(\mathrm{r}=0.832, p<0.01)$. This inversion had its highest frequency in the NN1 $(0.5)$ and lowest in the SR1 (0.013) populations (Fig. 3). In addition, it also positively correlated with altitude $(r=0.471, p<0.05)$ and negatively correlated with minimum annual air temperature $(r=-0.748$, $p<0.01)$. Inversion IIL-2 had a positively significant correlated with altitude $(r=0.778, p<0.01)$ and negatively correlation with minimum annual air temperature $(r=-0.570, p<0.01)$.

\section{Interspecific relationships}

Comparison of the chromosomes of $S$. aureohirtum with those of $S$. ruficorne reveals a high similarity of the banding patterns. Chromosomes I, II and IIIS of these species are identical. Only IIIL was different, whereby two multiple inversion complexes (IIIL-C and IIIL-6, Fig. 2f) were found. The IIIL-C needs two inversions to derive the sequence of IIIL of $S$. ruficorne. Inversion IIIL-6 is the first step in a series of five inversions needed to derive the IIIL sequence of S. ruficorne (see Bedo 1989).

Compared with the $S$. ornatipes standard map, the short arm of chromosome I (IS) has two simple fixed inversions (IS-4 and IS-5, IS-1 and IS-2 as in S. ruficorne, respectively) and a multiple inversion complex for which homology of the banding pattern could not be resolved (IS-C as in $S$. ruficorne). On the long arm (IL), there are two simple fixed inversions (IL-3 and IL-6, IL-3 and IL4 as in S. ruficorne) and the overlapping inversions IL-4 and IL-5 (IL-1 and IL-2 as in S. ruficorne). A simple fixed inversion was found on chromosome IIS (IIS-1, IIS-2 as in S. ruficorne) compared with the standard map of $S$. ornatipes. On the long arm, a simple fixed inversion (IIL-4, IIL-5 as in S. ruficorne) and a multiple inversion complex (IIL-C) were found. This complex inversion needs a sequence of five steps of rearrangements to derive it (see Bedo 1989). The short arm of chromosome III (IIIS) was identical. On the long arm, a simple fixed inversion (IIIL-6) was found (Fig. 2f). The phylogenetic relationship of $S$. aureohrtum, $S$. ruficorne, and the $S$. ornatipes complex, based on chromosome rearrangements is shown in Fig. 4.

\section{Discussion}

Most of the inversions (12 of 14) are present at low frequency and geographically restricted to a particular population (i.e. rare inversion). This class of inversion has been reported in other studies of black flies (e.g. Bedo 1979b, Adler and Kachvorian 2001, Petrova et al. 2003) and of the Chironomidae (e.g. Sella et al. 2004, Pramual et al. 2008). Because they present at very low frequency and restricted in a particular population rare inversions are likely to originate recently (Aulard et al. 2002, Pramual et al. 2008).

Population genetic structure analysis revealed significant genetic differentiation $\left(F_{\mathrm{ST}}=0.092\right.$, $p=0.0002)$. The value of $F_{\mathrm{ST}}$ was similar to those of $S$. exiguum in Ecuador $\left(F_{\mathrm{ST}}=0.083\right)$ (Charalambous et al. 2005) but much lower than those of $S$. nakhonense $\left(F_{\mathrm{ST}}=0.651\right)$ (Pramual 2006), Prosimulium fuscum $\left(F_{\mathrm{ST}}=0.421\right)$ and Simulium decorum $\left(F_{\mathrm{ST}}=0.622\right)$ (Feraday and Leonhardt 1989). A significant relationship between the level of genetic differentiation $\left(\mathrm{D}_{\mathrm{A}}\right.$ values $)$ and geographic distance $(\mathrm{Km})$ between populations $(r=0.497, p=0.004)$ suggests that gene flow was limited by geographic distance. Population genetic studies in other black flies species also 
revealed that geographic distance was the major factor limiting gene flow in black flies. Pramual et al. (2005) and Charalambous et al. (2005) found that gene flow in S. tani and S. exiguum, respectively, was limited by geographic distance.

Departure from Hardy-Weinberg equilibrium in the PR1 population due to an excess of heterozygote of IIL-1 was detected. This situation could be due to several factors (e.g. selection, nonrandom mating) but because the frequency of this inversion was associated with minimum annual air temperature (see below), an excess of heterozygotes of this inversion was likely influence by the effect of selection due to heterozygote advantage.

Significant differentiation for IIL-1 heterozygotes between sexes (Table 3) indicates that this inversion was partially linked to sex. Partial sex-linked for IIL-1 in three populations of S. aureohirtum may be indicating the first step for development of the sex-linked inversion in this species. This inversion may increase during the evolutionary time and complete sex-linked (i.e. 100\% sex-linked inversion) can be achieve.

In Simuliidae, sex is determined by sex-determining loci that can be located in any chromosome arms. However, for closely related species sex-determining loci tend to be restricted to the same chromosome arm. Partial sex-linked for IIL-1 indicated that the sex-determining loci of S. aureohirtum located in long arm of chromosome II (IIL). Other species in the S. ruficorne group which sex-linked inversion was found in IIL are S. ruficorne (Bedo 1989) and S. ornatipes A (Bedo 1977).

Clinal variation for the inversion polymorphisms of $S$. aureohirtum was found with latitude (IIL-1), altitude (IIL-2) and minimum annual temperature (IIL-1 and IIL-2). Clinal variation of inversion has been reported for several species of Drosophila such as Drosophila melanogaster (Knibb 1982), D. pseudoobscura, D. persimilis (Dobzhansky 1948) and D. mediopunctata (Ananina et al. 2004). However, only one report indicates clinal variation of the inversion with environmental factors in Simulium. Charalambous et al. (2005) found a significant relationship between inversion frequency and altitude and water current velocity in S. exiguum. The latitudinal cline in S. aureohirtum, to the best of our knowledge, is the first report in Simulium.

Clinal variation of an inversion with geography and environment is thought to be maintained by selection (e.g. Knibb et al. 1981, Knibb 1982). However, clinal variation could also be due to other factors such as the combined effect of genetic drift and gene flow without selection (Vasemägi 2006). The significant relationship of IIL-1 with latitude $(r=0.810, p<0.001)$ could be due either to selection or neutral effect such as migration and genetic drift. The IIL-1 inversion could have originated in the North and moved southward, resulting in a decrease in the frequency of the inversion with latitude. However, other lines of evidence suggest that it was likely maintained in populations by selection. This inversion was not only related to latitude but also to elevation $(r=0.471, p<0.05)$ and minimum annual air temperature $(r=-0.618, p<0.001)$.

Several studies have found a relationship between inversion polymorphisms and temperature. Stalker (1980) found that the standard sequence of the chromosomes of Drosophila melanogaster was involved in adaptation to cold temperature. Pramual et al. (2008) found an association between inversions and water temperature in Chironomus circumdatus. Etges et al. (2006) found that frequency shifts in the chromosome inversions in D. robusta was a response to recent climatic change. Knibb (1982) found an association of the inversion polymorphism with annual temperature in $D$. melanogaster. Molecular study found that a thermal tolerance gene in D. melanogsater located within an inversion shows a latitudinal cline (Anderson et al. 2003). Although we do not have enough evidence to conclude that the latitudinal cline of IIL-1 was maintained by selection, we hypothesize that clinal variation of the IIL-1 inversion was influenced by selection and the inversion IIL-1 was involved in adaptation to cold weather. Further study needs to test about the role of IIL-1 on the local adaptation.

Inversion IIL-2 also shows clinal patterns. This inversion was associated with altitude 
$(r=0.778 p<0.001)$ (i.e. altitudinal cline) and also significantly related to minimum annual air temperature $(r=-0.570, p<0.001)$. Nonetheless, unlike IIL-1 in which the frequency was high in each population ( $1.3 \%$ to $50 \%$ see Table 2$)$, the frequency of IIL-2 was low $(0.9 \%$ to $6.7 \%$ see Table 2$)$ but was geographically widespread. Thus, it is unlikely that the low frequency of the inversion was maintained in the population by selection. Instead, IIL-2 more likely is a relict of an ancestral polymorphism.

Simulium aureohirtum was assigned to the Simulium ruficorne species group based on morphology (Crosskey 1969). Homology of polyetene chromosome banding patterns of S. aureohirtum with those of $S$. ruficorne and $S$. ornatipes indicated that they are closely related and support the assignment of $S$. aureohirtum to the $S$. ruficorne species group. Polytene chromosome analysis of $S$. ruficorne, $S$. ornatipes and $S$. neornatipes indicates a close relationship among these species, with about $90 \%$ homology of the banding patterns with the standard chromosome maps (Bedo 1989). However, because $S$. ornatipes and $S$. neornatipes are distributed in Australia and New Caledonia, respectively, whereas $S$. ruficorne is distributed mainly in Africa and the Middle East, Bedo (1989) suggested that there should be cytologically intermediate species in Asia. Comparison of the chromosome map of $S$. aureohirtum with that of $S$. ruficorne and $S$. ornatipes-neornatipes supports Bedo's hypothesis. The map of $S$. aureohirtum is almost identical to that of $S$. ruficorne except for IIIL, in which two complex inversions differentiate these two species. According to the chromosome banding sequences, $S$. aureohirtum is more closely related to $S$. ruficorne than to the $S$. ornatipes-neornatipes group. Chromosomal and molecular studies in other species of this group would reveal more details of the species relationships.

In conclusion, our study revealed that clinal variation of inversions occurred in S. aureohirtum indicating that selection might be involved. Further study, using samples from a wider geographic area and long-term sampling, would be needed to test the hypothesis that the latitudinal cline in $S$. aureohirtum is maintained by selection. We found no evidence for the sibling species in $S$. aureohirtum but samples from a broader geographic range would probably reveal sibling species. A close relationship between $S$. aureohirtum and S. ruficorne is not unexpected given that they have a continuous geographic distribution. Comparison of the chromosomes with other species will give more details of the species relationships. Molecular study also could be used for phylogenetic inference.

\section{Acknowledgements}

This work was financially supported by grants from Mahasarakham University (Grant Year 2007), Commission on Higher Education and Thailand Research Fund (Grant No. MRG5080363) and the TRF/BIOTEC Special Program for Biodiversity Research and Training Program (Grant BRTR_25003). We would like to thanks Mr. Noppanon Pinpradub for his help in cytological techniques.

\section{References}

Adler P. H. and Crosskey R. W. 2008. World blackflies (Diptera: Simuliidae): A fully revised edition of the taxonomic and geographical inventory. Available at http://entweb.clemson.edu/biomia/pdfs/blackflyinventory.pdf

— and Kachvorian E. A. 2001. Cytogenetis of the Holarctic black fly Simulium noelleri (Diptera: Simuliidae). Can. J. Zool. 79: 1972-1979.

Ananina G., Peixoto A. A., Bitner-Mathé B. C., Souza W. N., Silva L. B., Valente Vera L. S. and Klaczko L. B. 2004. Chromosomal inversion polymorphism in Drosophila mediopunctata: seasonal, altitudinal, and latitudinal variation. Genet. Mol. Biol. 27: 61-69.

Anderson A. R., Collinge J. E., Hoffmann A. A., Kellett M. and McKechnie S. W. 2003. Thermal tolerance trade-offs associated with the right arm of chromosome and marked by hsr-omega gene in Drosophila melanogaster. Heredity 90: 195-202. 
Aulard S., David J. R. and Lemeunier F. 2002. Chromosomal inversion polymorphism in Afrotropical populations of Drosophila melanogaster. Genet. Res. 79: 49-63.

Bedo D. G. 1977. Cytogenetics and evolution of Simulium ornatipes Skuse (Diptera: Simuliidae) I. Sibling speciation. Chromosoma 64: 37-65.

— 1979a. Cytogenetics and evolution of Simulium oratipes Skuse (Diptera: Simuliidae). II. Temporal variation in chromosomal polymorphisms and homosequential sibling species. Evolution 33: 296-308.

— 1979b. Cytogenetics and evolution of Simulium ornatipes Skuse (Diptera: Simuliidae). III. Geographic variation of chromosomal polymorphisms and species divergence. Evolution 33: 309-331.

- 1989. A cytological study of Simulum ruficorne (Diptera: Simuliidae) and its relationship to the S. ornatipes species complex. Genome 32: 570-579.

Bohonak, A. J. 2002. IBD (Isolation by Distance): a programme for analysis of isolation by distance. J. Hered. 93: $153-154$.

Brunetti, E. 1911. New Oriental Nematocera. Rec. Indian Mus. 4: 259-316.

Charalambous, M., Lowell, S., Arzube, M. and Lowry, C. A. 2005. Isolation by distance and a chromosomal cline in the Cayapa cytospecies of Simulium exiguum, the vector of human onchocerciasis in Ecuador. Genetica 124: 41-59.

Crosskey, R. W. 1969. A re-classification of the Simuliidae (Diptera) of Africa and its islands. Bull. Br. Mus. (Nat. Hist.) Entomol. Suppl. 14: 1-195.

Dobzhansky, T. 1948. Genetics of natural populations. XVI. Altitudinal and seasonal changes produced by natural selection in certain populations of Drosophila pseudoobscura and Drosophila persimilis. Genetics 33: 158-176.

Etges, W. J., Arbuckle, K. L. and Levitan, M. 2006. Long-term frequency shifts in the chromosome polymorphisms of Drosophila robusta in the Great Smoky Mountains. Biol. J. Linn. Soc. Lond. 88: 131-141.

Feraday, R. M. and Leonhardt, K. G. 1989. Absence of population structure in black flies as revealed by enzyme electrophoresis. Genome 32: 531-537.

Goudet, J. 1995. FSTAT (vers. 1.2): a computer program to calculate $F$-statistics. J. Hered. 86: 485-486.

- 2001. FSTAT, A program to estimate and test gene diversities and fixation indices, Verrsion 2.9.3. University of Lausanne, Lausanne, Switzerland. Available from URL: http://www.unil.ch/izea/softwares/fstat.html.

Hunter, F. F. 2002. Polytene chromosomes of Simulium craigi (Diptera: Simuliidae). Genetica 114: 207-215.

Knibb, W. R. 1982. Chromosome inversion polymorphisms in Drosophila melanogaster II. Geographic clines and climatic associations in Australasia, North America and Asia. Genetica 58: 213-221.

—, Oakeshott, J. G. and Gibson, J. B. 1981. Chromosome inversion polymorphisms in Drosophila melanogaster. I. Latitudinal clines and associations between inversions in Australian populations. Genetics 98: 833-847.

Kuvangkadilok, C., Boonkemtong, C., Phayuhasena, S. and Baimai, V. 2003. Larval polytene chromosome of black flies (Simulium) of Thailand. I. Comparison among five species in the subgenus Gomphostilbia Enderlein. Genetica 118: 69-81.

—, Phayuhasena, S. and Baimai, V. 1999. Poplation cytogenetic studies on Simulium feuerborni Edwards (Diptera: Simliidae) from northern Thailand. Genome 42: 80-86.

Leonhardt, K. G. and Feraday, R. M. 1989. Sex chromosome evolution and population differentiation in the Eusimulium aureum group of black flies. Genome 32: 543-549.

Mantel, N. 1967. The detection of disease clustering and a generalized regression approach. Cancer Res. 27: $209-220$.

McCreadie, J. W., Adler, P. H., Grillet, M. E. and Hamada, N. 2006. Sampling and statistics in understanding distributions of black fly larvae (Diptera: Simuliidae). Acta. Entomol. Sin. Suppl. 89-96.

Ota, T. 1993. DISPAN: Genetic Distance And Phylogenetic Analysis. Pennsylvania State University, University Park, PA.

Petrova, N. A., Chubareva, L. A., Adler, P. H. and Kachvoryan, E. A. 2003. Cytogenetic features of blackfly Wilhelmia paraequina Puri (Diptera: Simuliidae) from Armenia. Russ. J. Genet. 39: 32-40.

Pramual, P. 2006. Population genetic structure of black flies (Diptera: Simuliidae) from Thailand inferred from mitochondrial DNA sequences. Ph.D. Thesis, Mahidol Universty, Bangkok, Thailand.

—, Gomontean, B., Buasay, V., Srikhamwiang, N., Suebkar, P., Niamlek, C., Donsinphoem, Y. and Chalat-Chieo, K. 2008. Population cytogenetics of Chironomus circumdatus Kieffer, 1921 (Diptera, Chironomidae) from Thailand. Genetica doi: 10.1007/s10709-008-9255-9.

—, Kuvangkadilok, C., Baimai, V. and Walton, C. 2005. Phylogeography of the black fly Simulium tani (Diptera: Simuliidae) from Thailand as inferred from mtDNA sequences. Mol. Ecol. 14: 3989-4001.

Rodríguez-Trelles, F., Alvarez, G. and Zapata, C. 1996. Time-Series analysis of seasonal changes of the O inversion polymorphism of Drosophila subobscura. Genetics 142: 179-187.

Rothfels, K. H. 1989. Speciation in blackflies. Genome 32: 500-509.

— and Dunbar, R. W. 1953. The salivary gland chromosomes of black fly Simulium vittatum Zett. Can. J. Zool. 31: $226-241$.

Sella, G., Bovero, S., Ginepro, M., Michailova, P., Petrova, N., Robotti, C. A. and Zelano, V. 2004. Inherited and somatic cytogenetic variability in Palearctic populations of Chironomus riparius Meigen 1804 (Diptera, Chironomidae). Genome 47: 332-344.

Stalker, H. D. 1980. Chromosome studies in wild populations of Drosophila melanogaster. II. Relationship of inversion fre- 
quencies to latitude, season, wing-loading and flight activity. Genetics 95: 211-223.

Takaoka, H. 1979. The blackflies of Taiwan (Diptera: Simuliidae). Pac. Insect. 20: 365-403.

— and Davies, D. M. 1996. The blackflies (Diptera: Simuliidae) of Java, Indonesia. Bishop Museum Press, Honolulu USA.

Unima, P. A., Weeks, A. R., Kearney, M. R., McKechnie, S. W. and Hoffmann, A. A. 2005. A rapid shift in a classic clinal pattern in Drosophila reflecting climate change. Science 308: 691-693.

Vasemägi, A. 2006. The adaptive hypothesis of clinal variation revisited: single-locus clines as a result of spatially restricted gene flow. Genetics 173: 2411-2414.

Weir, B. S. and Cockerham, C. C. 1984. Estimating F-statistics for the analysis of population structure. Evolution 38: $1358-1370$. 